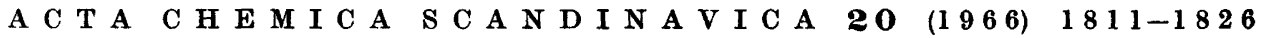

\title{
On the Solubility of Carbon Dioxide in Molten Alkali Halides
}

\author{
D. B R A T LA ND, K. GR J O THEIM, C. KROHN and K. MOTZFELDT
}

\author{
Institute of Inorganic Chemistry, The Technical University of Norway, and \\ Metallurgical Committee of the Royal Norwegian Council for Scientific and \\ Industrial Research, Trondheim, Norway
}

\begin{abstract}
The solubilities of $\mathrm{CO}_{2}$ at 1 atm pressure in molten $\mathrm{NaCl}, \mathrm{KCl}$, $\mathrm{KBr}$, and $\mathrm{KI}$ have been redetermined in the temperature range $700-$ $1000^{\circ} \mathrm{C}$. Three different methods have been employed; a volumetric, a thermogravimetric, and a "chilling" method. The results of the three methods are in satisfactory agreement. With the Henry's law constant $K$ expressed in terms of moles of $\mathrm{CO}_{2} / \mathrm{ml}$ solvent-atm, the results may be expressed by the following empirical equations:

$\mathrm{NaCl}: \log K=-5.12-1280 / T$

$\mathrm{KCl}: \log K=-5.28-980 / T$

$\mathrm{KBr}: \log K=-5.24-880 / T$

A simple hole model for the liquid, used by previous investigators to correlate solubilities of inert gases, is shown to yield good agreement also in the case of carbon dioxide. The entropy change for transfer of $\mathrm{CO}_{2}$ from the gas phase to the molten salt, at equal concentrations in the two phases, is found to be of the order of -1 e.u./mole.
\end{abstract}

\begin{abstract}
A s part of a general research program on the chemistry of light metal proA duction, an investigation on gas solubilities in molten salts was initiated some years ago. The primary aim was to elucidate the secondary reactions that may take place during the electrolysis of molten salts. As the study has progressed, however, interest has developed in gas solubilities also as a potential source of information on the structure of molten salts.

Some preliminary results on the solubilities of carbon dioxide in molten sodium chloride and potassium chloride have been reported previously. ${ }^{1}$ When comparing with the results of the present paper, however, it is seen that these preliminary results were almost a power of ten too high. The high results were caused by small amounts of nickel oxide from the nickel containers used in the previous work. The nickel oxide dissolved in the melt and enhanced the solubility because of the tendency to form carbonate ions. This point is further discussed in Appendix 1.

Information on carbon dioxide solubilities in molten salts is very limited in the literature. Haupin ${ }^{2}$ and Førland et al. ${ }^{3}$ have measured solubilities of $\mathrm{CO}_{2}$ in cryolite-alumina mixtures. Solubilities of $\mathrm{CO}_{2}$ in molten silicate glasses
\end{abstract}


have also been reported, ${ }^{4,5}$ but the mechanism of dissolution in these oxide systems would be expected to differ from that in the molten halides.

Ryabukhin ${ }^{6}$ has investigated the solubilities of chlorine in molten $\mathrm{NaCl}$, $\mathrm{KCl}$, and $\mathrm{MgCl}_{2}$. His results are of the same order of magnitude as the solubilities reported in the present paper; this gives some support to the view that the process is one of physical dissolution in both cases, and thus not very different from the dissolution of noble gases. ${ }^{7-9}$

\section{EXPERIMENTAL}

The problem to be solved was the determination of the amount of carbon dioxide which is dissolved in a known amount of molten salt at a specified temperature and gas pressure. The experimental approach previously employed ${ }^{1}{ }^{2}$ was that of removal of the dissolved carbon dioxide from the molten salt by stripping with an inert gas and subsequent absorption in Ascarite. This method required a somewhat intricate design of the container for the molten salt, with severe problems of the container material. ${ }^{1,10}$

An alternative approach is the direct determination of the volume change of the gas (at constant pressure) caused by the dissolution in the melt. A third approach is to determine the weight gain of the sample caused by the absorption of the gas, that is, a thermogravimetric method. A fourth method resembles the "stripping method" in that the dissolved gas is removed from the salt before determination of its amounts. The removal in this case, however, is effected by freezing of the melt. This has been termed the "chilling method".

(a) Volumetric method. The equipment used for the volumetric measurements is shown in Fig. 1. In order to minimize spurious changes in gas volume, accurate control of temperature and pressure was required, and the dead volume had to be kept to a minimum. The latter requirement was met by using for the reaction chamber two concentric, closed-end silica glass tubes with the crucible supported at the upper end of the inner tube. The silica tubes were placed inside a resistance-heated tube furnace of standard design. ${ }^{11}$ The temperature of the furnace was kept constant within $\pm 0.1^{\circ} \mathrm{C}$ by means

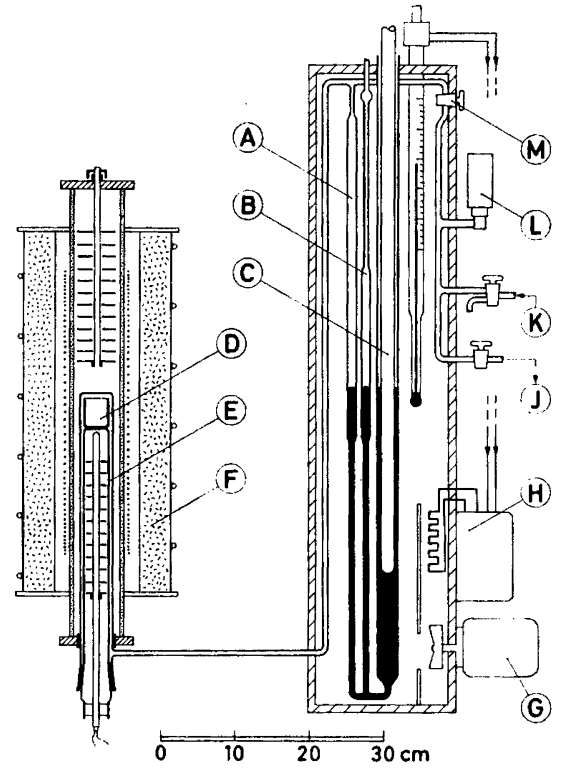

Fig. 1. Apparatus for volumetric measurements. A: Gas burette. B. Levelling tube. C: Glass piston to adjust level of mercury. D:Platinum crucible with molten salt. E: Concentric silica glass tubes, closed upper end, ground joint at lower end. F: Tube furnace with Kanthal heater windings. G: Fan motor. H: Power control for thermostat heater. J: To rotary vacuum pump. K: Gas inlet. L: Pirani gauge. M: Stopcock, shut during volume measurement. 
of a sensitive two-position control circuit. Constant temperature was equally important for the gas burette section, which was enclosed in an air thermostat kept at $25.0 \pm 0.3^{\circ} \mathrm{C}$. The mercury levels on both sides of the burette (A and $B$ on Fig. 1) were equalized by means of the glass piston (C) before each volume reading.

It is known from the literature ${ }^{12}$ as well as from separate experiments ${ }^{13,14}$ that all organic polymers commonly used as gasket materials dissolve significant amounts of carbon dioxide. (For most of the materials the solubility is of the order of 1:1 by volume at room temperature and 1 atm of $\mathrm{CO}_{2}$.) Consequently, gasket joints were avoided in the equipment, and stopcock grease was used sparingly. By separate blank runs, no absorption of $\mathrm{CO}_{2}$ by the silica tube could be detected within the accuracy of the apparatus.

It was virtually impossible to start a measurement at zero time with a constant carbon dioxide pressure throughout the system and no gas dissolved in the melt. The measurements had instead to be based on the assumption that the solubility of $\mathrm{CO}_{2}$ in the solid salt is nil. By observations at temperatures closely below and closely above the melting point, correcting for the gas expansion due to the temperature change, and for the known expansion of the salt on melting, ${ }^{15 *}$ the solubility in the molten salt closely above the melting point was measured.

The over-all uncertainty in the determination of the absorbed volume was estimated to $\pm 0.05 \mathrm{ml}$. This is to be compared to a total volume of about $0.2 \mathrm{ml}$ of dissolved gas (in about $15 \mathrm{~g}$ of salt). The estimated uncertainty thus amounted to about $25 \%$. This large relative uncertainty was primarily due to the fact that the observed solubilities were much smaller than anticipated at the start of this work. A weak point in the apparatus was the dual function of the gas burette. For accuracy in the volume measurement, the burette should have narrow bore. For precise observation and adjustment of pressure, on the other hand, it should be of wide bore tubing to avoid capillary effects. The two requirements were incompatible, and the only way to improve the precision was to separate the two functions of volume and pressure observation. It was found difficult, however, to improve the accuracy sufficiently to warrant continued measurements by this technique, which was finally abandoned in favour of the two following methods. The volumetric method has been described here mainly because the few measurements that were obtained ${ }^{14}$ (included in Table 1) are in reasonable accord with the results of the other methods and thus serve to substantiate the validity of these results.

(b) Thermogravimetric method. The equipment used for the thermogravimetric experiments is shown in Fig. 2. An ordinary knife-edge analytical balance was converted to a recording balance by means of a position transducer and a force element mounted on opposite ends of the balance beam, in conjuction with an all-transistor electronic servo circuit.** For these measurements, the servo circuit and the size of the force element were adjusted so that a weight change of $5 \mathrm{mg}$ corresponded to a full deflection of $20 \mathrm{mV}$ on the potentiometric recorder. With a total weight of salt of about $100 \mathrm{~g}$, this means an accuracy better than 1 part in $10^{6}$, which was necessary for the present measurements. Larger weight changes were counterbalanced by a set of weights manually operated through vacuum-tight rotary seals.

The balance was mounted inside a glass bell jar above a tube furnace of standard design.11 The balance and furnace compartments were vacuum tight and were evacuated and degassed with the furnace at about $600^{\circ} \mathrm{C}$ for several hours before the start of each series of solubility measurements. The heating to temperature was done under a suitable pressure of an inert gas (argon) and the furnace temperature maintained constant within $\pm 0.3^{\circ} \mathrm{C}$ by means of a voltage stabilizer in the furnace current supply. (Two-position control was found occasionally to cause oscillations in the recorded weight and consequently was not used). The temperature of the balance compartment had likewise to be kept constant to avoid variations in the buoyancy of the tare; this was achieved by maintaining the room temperature constant within $\pm 0.5^{\circ} \mathrm{C}$. The temperature within the balance compartment was measured by means of a thermistor.

Several experimental problems are encountered in this gravimetric method:

* The volume change observed in the burette at temperature $T_{\mathrm{b}}$, caused by the volume change of the salt at its melting point $T_{\mathrm{m}}$, is $\Delta V_{\mathrm{obs}}=\Delta V_{\mathrm{m}} T_{\mathrm{b}} / T_{\mathrm{m}}$.

** Designed and manufactured by the Division of Automatic Control of SINTEF (The Engineering Research Foundation at the Technical University of Norway).

Acta Chem. Scand. 20 (1966) No. 7 


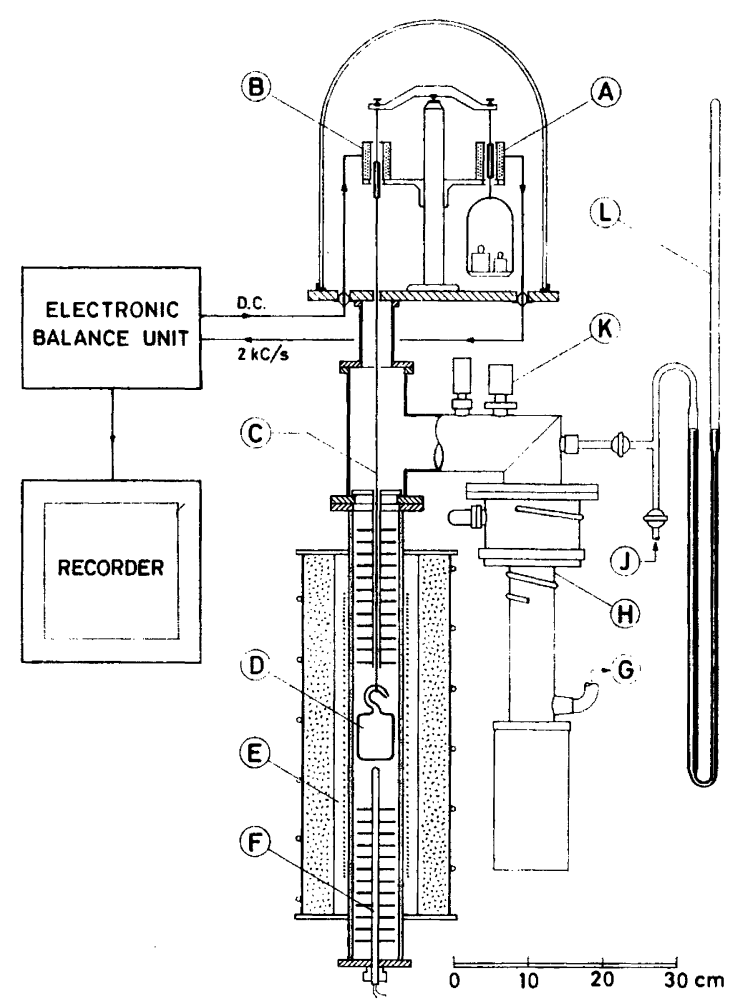

Fig. 2. Recording thermo-vacuum-balance. A: Position transducer (differential transformer). B: Force element (permanent bar magnet suspended in solenoid). C: Suspension wire, 60Pt40Rh. D: Silica glass container with molten salt. E. Tube furnace with Kanthal heater windings, impervious refractory tube. (Mullite-base refractory, Pythagoras brand from W. Haldenwanger, Berlin-Spandau, Germany.) F: Thermocouple sheath, Pt/90Pt10Rh thermocouple. G: To forevacuum pump. H: Oil diffusion pump with baffle valve. J: Gas inlet. K: Pirani and Penning gauges. L: Mercury manometer.

Manually operated weight change mechanism on balance not shown. Balance and electronic circuit schematic, rest of equipment drawn to scale.

(1) The vapour pressures of the salts under consideration are sufficient to cause considerable weight loss by evaporation. To cut down evaporation, only a very small opening in the container was allowed. Fig. 3 shows the shape of the employed silica glass vessels. Even with a very narrow opening (0.1 to $0.2 \mathrm{~mm}$ diam., several millimetre's length) heating in a vacuum above the melting point caused excessive weight loss. The experiments were consequently done by determining the weight of gas absorbed when changing from a low to a higher carbon dioxide pressure.

(2) The change in buoyancy caused by a change from a low to a higher gas pressure (or vice versa) exceeded by an order of magnitude the weight change caused by the dissolved (or expelled) gas. This, in combination with the slow but significant weight change caused by evaporation, made it virtually impossible to determine directly the weight of the sample at the start of absorbtion. This weight had to be determined from the shape of the recorded absorption curve. 


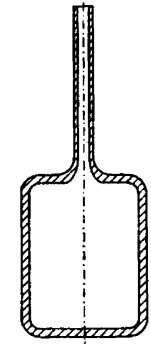

A

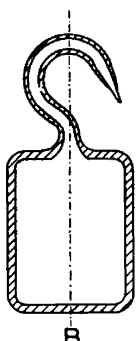

$\mathrm{B}$
Fig. 3. Silica glass vessel for thermogravimetric measurements. A: Shape prior to filling. B: Shape during measurements.

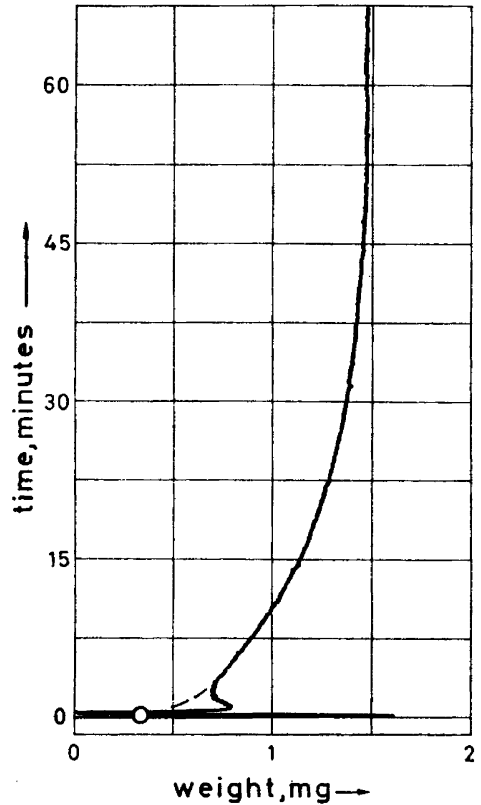

Fig. 4. Typical curve of weight change versus time, traced from original recorder chart. Carbon dioxide pressure in system changed from 10 torr to 700 torr at zero on time scale. Point marked with open circle represents starting points as determined from the graph Fig. 5. Dashed line indicates parabola which should ideally be obtained.

Fig. 4 shows a typical tracing. A characteristic feature is that the curve shows no definite starting point after admittance of gas. During the short interval when gas is admitted, the balance is set in oscillations (horizontal parts of the tracing in Fig. 4). Next follows an S-shaped part of the curve before it assumes the expected, parabola-like shape.*

In order to extrapolate the curve to its true origin it was assumed that the rate of dissolution of the gas in the molten salt obey the same general law as the diffusion in a solid slab. The weight of the gas that is dissolved at any time is expressed as fraction of the total solubility, and this "fractional saturation" $F$ is plotted against the square root of time. The resulting curve should then be a straight line up to about $60 \%$ saturation. In Fig. 5, the data from Fig. 4 are presented in this way. The plotted $F$ values depend on the assumed value for the total weight change; the correct value is found as the one which leads to a straight line through the origin. It is seen from Fig. 5 that the correct value for the total weight change may be confidently established by this procedure. The

* The probable explanation of the S-shape is as follows. When cold gas is admitted to the furnace, it will be heated more slowly in the center of the furnace than in contact with the hot furnace walls. Consequently, convection currents will be set up in the gas, with a "wind" falling down on the sample vessel increasing its apparent weight. After a few minutes, uniform gas temperature is obtained within the furnace and the apparent weight decreases.

Acta Chem. Scand. 20 (1966) No. 7 


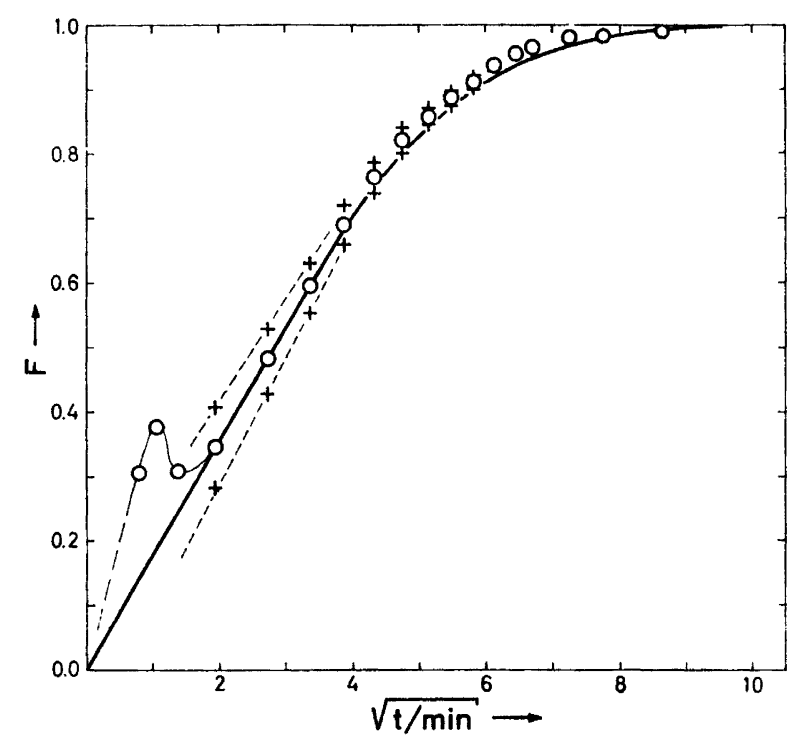

Fig. 5. Data from Fig. 4 (measured on the original recorder chart) plotted versus square root of time. Ordinate represents fractional saturation = fraction of total weight change. Plotted points are derived from assumed values for this total weight change as follows: Upper set of crosses, $1.25 \mathrm{mg}$; lower set of crosses, $1.03 \mathrm{mg}$; circles, $1.14 \mathrm{mg}$. The latter value is accepted since the straight part of the curve extrapolates through the origin. Full-drawn line gives the theoretical shape of the curve for diffusion in a solid slab.

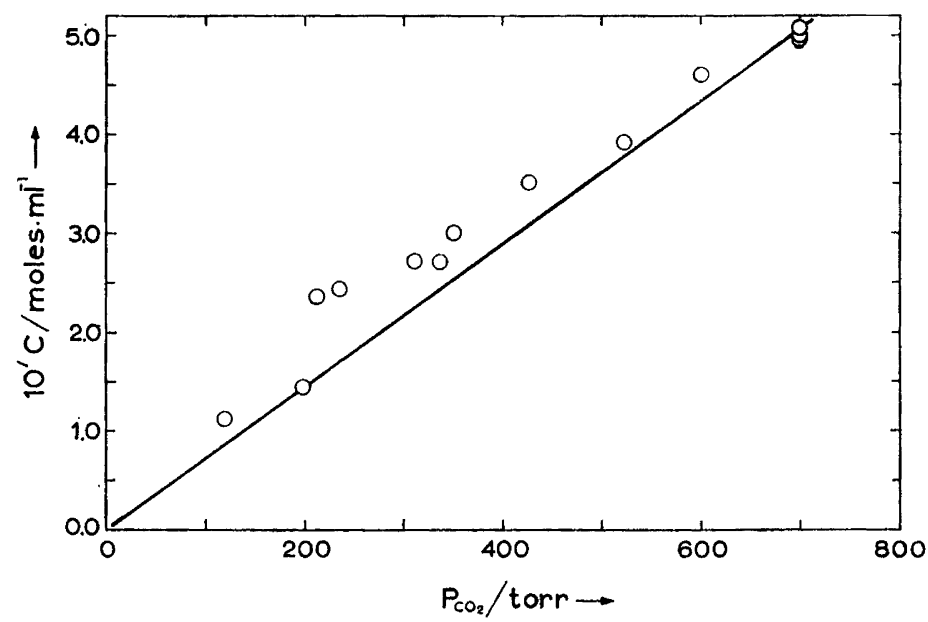

Fig. 6. Thermogravimetrically determined solubility of $\mathrm{CO}_{2}$ in molten $\mathrm{NaCl}$ as a function of $\mathrm{CO}_{2}$ pressure, at a constant temperature of $833^{\circ} \mathrm{C}$. 
full-drawn line represents the theoretical curve for diffusion in a solid slab, ${ }^{16}$ see also Appendix 2.

By this graphical treatment of the observed weight changes, the amount of absorbed gas for each run was determined. It was mentioned above that the measurements took place between two fixed pressures, both of which were above zero and below 1 atm. Conversion of the measured data to solubilities at $1 \mathrm{~atm}$ carbon dioxide pressure requires the use of Henry's law. It is hardly to be doubted that this law will be valid at these low concentrations of solute, nevertheless an experimental check on this point was attempted. Fig. 6 shows a plot of the observed solubilities in sodium chloride at a constant temperature of $8^{\circ} 3^{\circ} \mathrm{C}$ and varying carbon dioxide pressures. The agreement with the straight

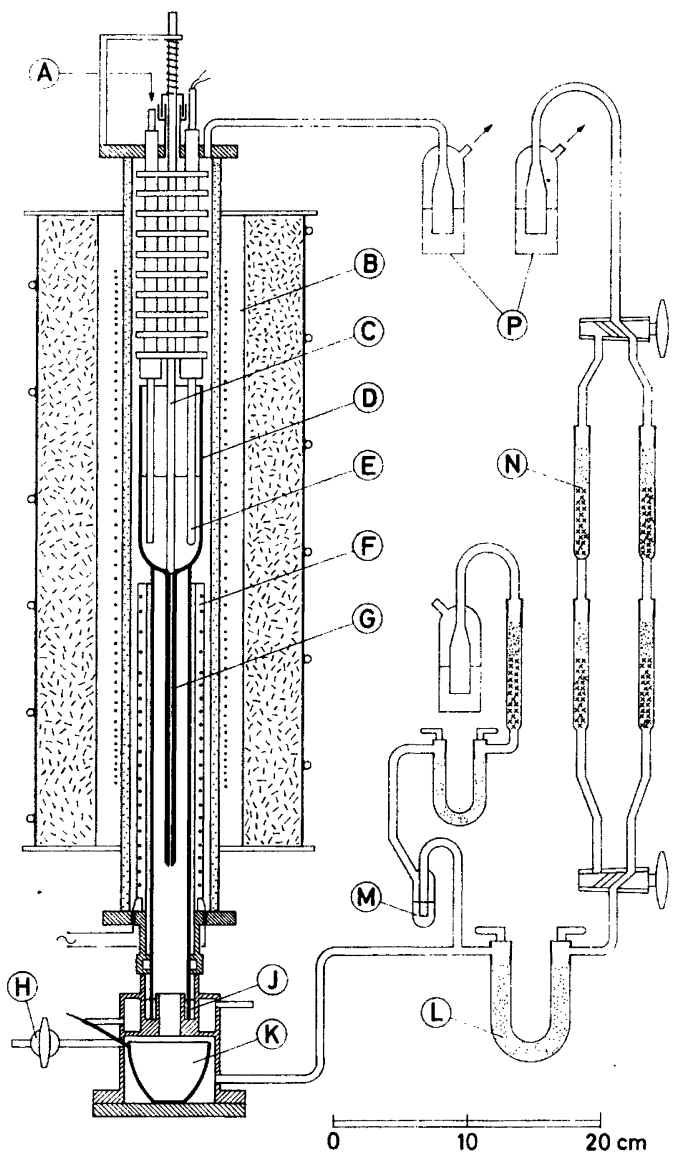

Fig. 7. Apparatus for the chilling method. A: Carbon dioxide inlet. B: Tube furnace with Kanthal heater windings. C: Alumina tap rod, spring loaded from top. D: Silica glass container with molten salt. E: Thermocouple sheath. F: Auxiliary furnace with Nichrome heater windings. G: Silica glass capillary. H: Stopcock on nitrogen inlet. J: Mercury seal (to avoid organic polymer gaskets that may absorb carbon dioxide). $\mathrm{K}$ : Water-cooled chilling chamber with silica crucible. L: Drying tube with Dehydrite. M: Mercury relief valve (to relieve the momentary overpressure which arises when molten salt enters the chilling chamber). N: Absorbtion vessels filled with Ascarite plus Dehydrite. P: Glycerolfilled bubble traps on gas outlets.

Acta Chem. Scand. 20 (1966) No. 7 
line is about as good as could be expected, considering the extremely small weight changes that are observed and the several sources of error. 'The thermogravimetrically determined solubilities at various temperatures, converted to 1 atm carbon dioxide, are represented by the black circles on Fig. 8 .

(c) Chilling method. As mentioned above, the volumetric measurements had to be based on the assumption that the solubility of the gas in the solid salt is negligible compared to that in the liquid. If this is true, the solubility measurements may be carried out most simply by cooling of the salt and collection of the expelled gas. This method was used previously by Førland et $a l .{ }^{3}$ who performed their experiments by rapidly removing the crucible with its contents from the furnace and placing it in a separate cooling chamber. A somewhat more refined technique was used for the smaller solubilities encountered in the present work.

Fig. 7 shows the essential details of the apparatus. The tube furnace $B$ and equipment for temperature control are identical with that of the volumetric method. The salt is charged into the silica glass crucible $D$, where it is melted and saturated with carbon dioxide. Next, the auxiliary furnace $F$ is switched on to melt the frozen salt column in the capillary $G$, and the ground-in alumina rod $C$ is lifted to tap out about two-thirds of the melt. (The level of the liquid in the crucible is sensed by means of two isolated platinum electrodes connected to a battery and a pilot light.) The salt runs into the chilling chamber $K$ where it solidifies, and the expelled carbon dioxide is transported by a stream of pure nitrogen into the absorption vessels $\mathbf{N}$.

The chilling method proved to be more expedient and less tedious than the two others while giving results of comparable or better accuracy.

(d) Chemicals. All chemicals were of the pro analysi quality (E. Merck A. G., Darmstadt, Germany). For the volumetric and thermogravimetric measurements, the salt was dried in situ, whereas the chilling method employed a pre-drying of the salts under vacuum at $450^{\circ} \mathrm{C}$ for $4 \mathrm{~h}$.

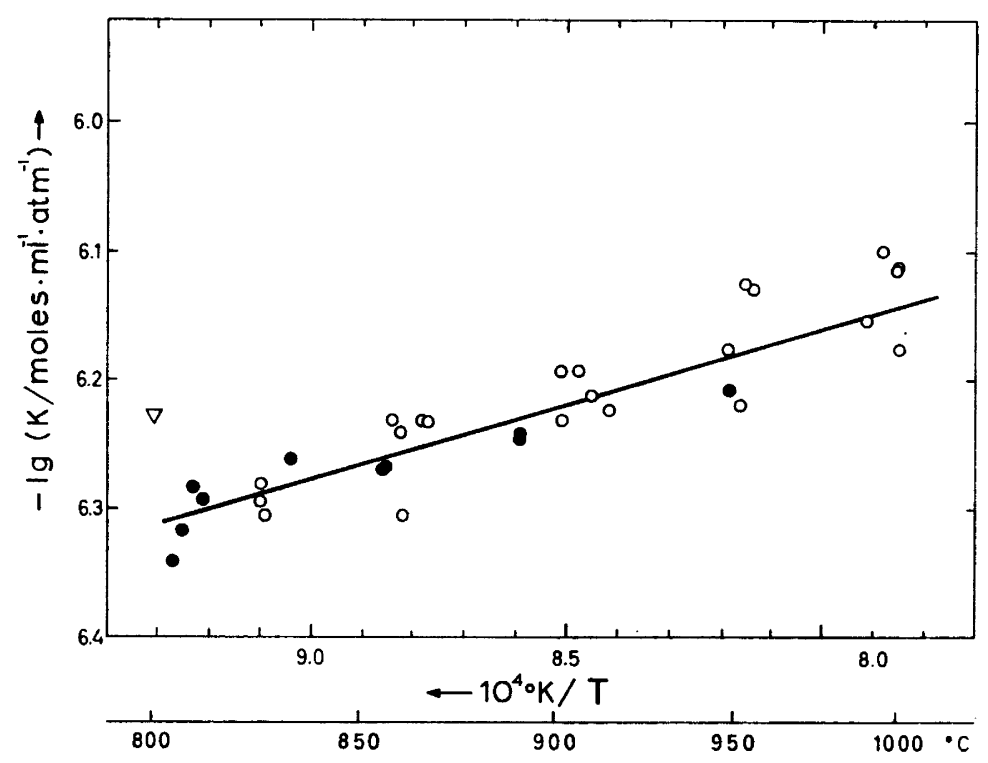

Fig. 8. Solubility of $\mathrm{CO}_{2}$ in $\mathrm{NaCl}$. Open circles: Chilling method. Filled circles: Thermogravimetric method. Triangle: Single measurement by volumetric method. 


\section{RESULTS}

In conformity with previous authors, ${ }^{7}$ the solubilities are expressed as moles of $\mathrm{CO}_{2}$ per $\mathrm{ml}$ of solvent at $1 \mathrm{~atm} \mathrm{CO}_{2}$ pressure. The necessary data for the densities of the molten salts are taken from Van Artsdalen and Yaffe. ${ }^{17}$ In Fig. 8, the results for the solubility in molten $\mathrm{NaCl}$ obtained by all three methods are plotted for comparison.

In Table 1 are given the solubilities in molten $\mathrm{NaCl}, \mathrm{KCl}, \mathrm{KBr}$, and $\mathrm{KI}$ at various temperatures, as obtained by the chilling method. The tabulated data are mean values from several experiments at each temperature. These mean values are plotted as functions of temperature in Fig. 9.

Table 1. Solubility of $\mathrm{CO}_{2}$ in molten alkali halides. Figures in italics obtained by the volumetric method, the rest by the chilling method.

\begin{tabular}{|c|c|c|c|c|}
\hline & $\stackrel{t}{{ }^{t} \mathrm{C}}$ & $\begin{array}{l}\text { No. of measure- } \\
\text { ments* }\end{array}$ & $\begin{array}{c}K \times 10^{7} \\
\text { moles.ml-1 atm } \\
(\text { mean value) }\end{array}$ & $\begin{array}{l}\text { Mean deviation } \\
\times \cdot 10^{7}\end{array}$ \\
\hline $\mathrm{NaCl}$ & $\begin{array}{l}829 \\
862 \\
904 \\
951 \\
997 \\
801\end{array}$ & $\begin{array}{l}5 \\
5 \\
7 \\
4 \\
6 \\
3\end{array}$ & $\begin{array}{l}5.20 \\
5.64 \\
6.19 \\
6.89 \\
7.58 \\
5.9\end{array}$ & $\begin{array}{l}0.35 \\
0.29 \\
0.20 \\
0.56 \\
0.47 \\
0.64\end{array}$ \\
\hline $\mathrm{KCl}$ & $\begin{array}{r}799 \\
851 \\
903 \\
912 \\
952 \\
1002 \\
776\end{array}$ & $\begin{array}{l}5 \\
5 \\
4 \\
2 \\
7 \\
6 \\
2\end{array}$ & $\begin{array}{l}6.45 \\
7.15 \\
7.90 \\
8.03 \\
8.57 \\
8.95 \\
7.2\end{array}$ & $\begin{array}{l}0.23 \\
0.20 \\
0.01 \\
0.24 \\
0.21 \\
0.19 \\
1.8\end{array}$ \\
\hline $\mathrm{KBr}$ & $\begin{array}{l}775 \\
829 \\
874 \\
927\end{array}$ & $\begin{array}{l}\mathbf{6} \\
\mathbf{6} \\
\mathbf{6} \\
\mathbf{6}\end{array}$ & $\begin{array}{r}8.46 \\
9.36 \\
9.80 \\
10.89\end{array}$ & $\begin{array}{l}0.14 \\
0.13 \\
0.20 \\
0.14\end{array}$ \\
\hline KI & $\begin{array}{l}700 \\
681\end{array}$ & $\begin{array}{l}3 \\
2\end{array}$ & $\begin{array}{r}19.2 \\
9.8\end{array}$ & $\begin{array}{l}0.6 \\
0.6\end{array}$ \\
\hline
\end{tabular}

* All runs were within $\pm 4^{\circ}$ of stated temperatures.

\section{DISCUSSION}

(a) Precision of experimental methods. The difficulties of the volumetric method were considered above and will not be further discussed here. In judging the accuracy of the two other methods, it should be remembered that both depend on the determination of very small weight changes. In the thermogravimetric method, a weight change of about $1 \mathrm{mg}$ is observed in a total 


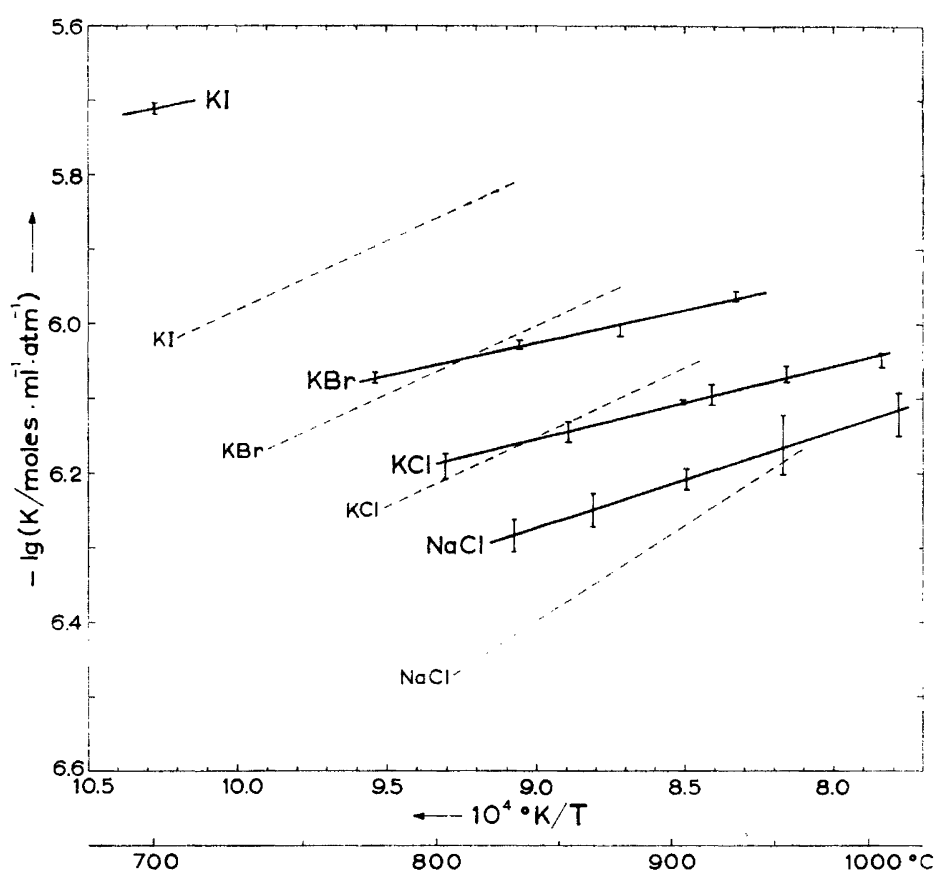

Fig. 9. Full-drawn curves: Solubility of $\mathrm{CO}_{2}$ in $\mathrm{NaCl}, \mathrm{KCl}, \mathrm{KBr}$, and $\mathrm{KI}$, results from chilling method. Each point on curves represents mean value from several experiments, vertical extension of point represents mean deviation (cf. Table 1).

Dashed curves: Theoretical solubilities from size of $\mathrm{CO}_{2}$ molecule and surface tension of molten salt, equation of Blander et al.

weight of about $100 \mathrm{~g}$, corresponding to a net change of 1 part in $10^{5}$. And this is observed with the sample at elevated temperature and under the influence of possible slight convection currents in the surrounding atmosphere as well as slight losses by evaporation.

The weighing problem is somewhat less severe in the chilling method. The weighed amount of $\mathrm{CO}_{2}$ is in the range of $1 \mathrm{mg}$ and the total weight of the absorption vessel is about $18 \mathrm{~g}$. The precision of the employed analytical balance is $0.02 \mathrm{mg}$, which gives an uncertainty of $\pm 2 \%$ in the results. Taking into account random effects from water absorption on the glass surface and minor differences in the handling and wiping of the absorption vessel, the random weighing error is estimated to $\pm 5 \%$.

It is gratifying that the results of the three different experimental methods are in essential agreement. It is noted in particular that the results from the chilling method (and the volumetric) depend on the assumption that the solubility in the solid salt is negligible, while the results of the thermogravimetric method do not. The agreement between the results thus substantiates the correctness of this assumption, which means that the approach of the chilling method is basically sound. While there may still be an uncertainty 
of some $\pm 10 \%$ in the reported values, the correct order of magnitude must be considered as definitely established.

(b) Effect of impurities in the salts. The observed solubilities are of the order of $0.001-0.002$ weight percent of $\mathrm{CO}_{2}$. This is the same order of magnitude as the limits of impurities stated for the reagent grade salts employed. Hence the possible effect of impurities cannot be dismissed without some consideration.

The impurities that may be present may be roughly grouped in three categories. First come the strongly basic impurities such as alkali oxide or hydroxide. This type of impurity is not separately listed in the specifications for the reagents. It is quite likely, however, that contact with the moisture of the atmosphere will result in some hydrolysis, forming hydroxyl ions that will not afterwards be effectively removed by drying. The resulting hydroxide or oxide content will subsequently react with the carbon dioxide to form carbonate ions. The alkali carbonates, however, are sufficiently stable so that their thermal decomposition, at temperatures up to $1000^{\circ} \mathrm{C}$ and in the presence of an inert gas, will proceed at an extremely low rate only. ${ }^{18}$ Hence these carbonate ions, once formed, will remain in the melt and will not influence the results of the subsequent measurements.

As a second group come the strictly neutral impurities like bromide or sulphate in the chloride, etc. This type, which constitutes the major part of the impurities likely to be present, will not be of any consequence for the solubility of carbon dioxide.

As a third possible cathegory, intermediate between the two above, come the weakly basic impurities that may lead to an enhanced reversible uptake of carbon dioxide. Nickel oxide has been shown to give this effect ( $c f$. Appendix 1) although the reactions involved are not well understood. In general, one might expect most transition-metal oxides to give similar effects. This type of impurity, however, is expected to be present in the reagent grade salts in extremely small amounts only. It may be noted also that the experiments described here have been done with samples of the same salt taken from jars with differing dates of manufacture, with satisfactory agreement among the results. Furthermore the solubilities in the different halides that have been investigated, show systematic differences in accordance with expectation (see the discussion below). It would be a very rare coincidence if the contents of transition metal oxides should show the same systematic variation. Hence it is concluded that this type of impurity is not responsible for any significant part of the solubilities reported here.

All reported results from the thermogravimetric and the chilling methods were obtained with the use of silica containers for the molten salts. It might be argued that the presence of an acidic oxide like silica might depress the solubility of carbon dioxide. The authors consider this quite unlikely, yet it might appear desirable with an experimental check on this point. The results from the volumetric method were obtained with the use of a platinum container and hence may be taken to indicate that the presence of silica makes no observable difference; but these results are few and of more doubtful accuracy than the rest. A series of attempts were done also by the thermogravimetric method to determine the solubility in molten sodium chloride 
contained in platinum. These attempts were unsuccessful, however, because excessive weight loss was found in all runs. To cut down evaporation, the platinum lid was solidly welded to the crucible after charging with salt, leaving only a tiny pinhole for the entrance of the gas. Still, evaporation losses were severe (remembering that a weight loss of $0.01 \mathrm{mg}$ per min is sufficient to ruin the experiment). It appears that the salt wets the platinum well enough to "creep" along the surface and out through the pinhole, in a manner similar to that frequently observed for fluoride melts. The difficulty could possibly be remedied by the use of a suitable noble metal alloy ${ }^{19}$ rather than pure platinum.

(c) Mechanism of dissolution. From the slope of the experimental curves on Fig. 9, values of the heat of dissolution $\Delta H_{\mathrm{d}}$ have been calculated, presented in the first column of Table 2. The change in free energy of the dissolution process at equilibrium is zero, hence the entropy of dissolution is $\Delta S_{\mathrm{d}}=$ $\Delta H_{\mathrm{d}} / T$.

As pointed out by Blander et al., ${ }^{8}$ the main contribution to this entropy change comes from the expansion of the gas from its concentration $C_{\mathrm{g}}$ in the gas phase (at $1 \mathrm{~atm}$ ) to the concentration $C_{\mathrm{d}}$ in the melt. This entropy change is

$$
\Delta S_{1}=-R \ln \left(C_{\mathrm{d}} / C_{\mathrm{g}}\right)=-R \ln \left(K \cdot R^{\prime} T\right)
$$

where $K$ has the same meaning as before, and $R^{\prime}$ is expressed in ml.atm.deg ${ }^{-1}$. The difference between this and the experimental entropy change should give the entropy change connected with the transfer of gas molecules from the gas phase to the melt (at equal concentrations):

$$
\Delta S_{2}=\Delta S_{\mathrm{d}}-\Delta S_{1}
$$

Values of $\Delta S_{\mathrm{d}}, \Delta S_{1}$ and $\Delta S_{2}$ (calculated at $1150^{\circ} \mathrm{K}$ ) are given in Table 2. It is seen that the transfer of $\mathrm{CO}_{2}$ molecules from the gas phase to the melt is accompanied by a small negative change in entropy, as has also been found for the dissolution of noble gases in molten halides. ${ }^{7-9}$ The small values found for $\Delta S_{2}$ here seem to indicate that the $\mathrm{CO}_{2}$ molecule does not lose any appreciable fraction of its rotational entropy when dissolved in the melt.

It is of interest to compare the observed solubilities with values calculated from a very simple model. ${ }^{20,8}$ The gas is first expanded as above, the free energy change of this is $\Delta G_{1}=-T \Delta S_{1}=+R T \ln \left(K R^{\prime} T\right)$. It is next assumed that the dissolution of one mole of $\mathrm{CO}_{2}$ in the liquid necessitates the creation of one mole of holes of sufficient size. The minimum size required is such that the internal area of each hole equals the external area of the $\mathrm{CO}_{2}$ molecule, let this area be designated $A$. The energy necessary to create one mole of holes is then $\Delta G_{2}=N A \gamma$, where $N$ is Avogadro's number and $\gamma$ is the surface tension. At equilibrium, $\Delta G=\Delta G_{1}+\Delta G_{2}=0$, this yields the very simple relation

$$
\ln \left(K R^{\prime} T\right)=-N A \gamma / R T
$$

Note that for numerical evaluation of this equation, $R$ and $\gamma$ must be expressed in the same energy units, while $R^{\prime}$ is expressed in ml.atm.deg ${ }^{-1}$ as before. 
Clearly this model represents an over-simplification. Among other things, it is assumed that the observable bulk surface tension $\gamma$ is representative also of the surface tension within a hole of molecular dimensions in the liqid. But, to quote Blander et al.:8 "Although the model is naive it yields an interesting correlation with experiment".

In order to evaluate the surface area $A$ of the $\mathrm{CO}_{2}$ molecule, it may be represented by two half-spheres joined by a short cylinder. The radius of the half-spheres, equal to that of the cylinder, is taken as the van der Waals radius for oxygen, $1.40 \AA,{ }^{21}$ and the length of the cylinder equals the $\mathrm{O}-\mathrm{O}$ distance in $\mathrm{CO}_{2}, 2.32 \AA .{ }^{21}$ This leads to a calculated surface area $A=45 \times$ $10^{-16} \mathrm{~cm}^{2}$. The necessary data for the surface tension are taken from Bloom et al. ${ }^{22}$ The solubilities thus calculated are represented by the dashed lines in Fig. 9. It is seen that the calculated values are in surprisingly good agreement with experiment.

Table 2.

\begin{tabular}{lllll}
\hline & $\begin{array}{l}\Delta H_{\mathrm{d}} \\
\mathrm{kcal}\end{array}$ & $\begin{array}{l}\Delta S_{\mathrm{d}} \\
\text { e.u. }\end{array}$ & $\begin{array}{l}\Delta S_{\mathrm{1}} \\
\text { e.u. }\end{array}$ & $\begin{array}{c}\Delta S_{2} \\
\text { e.u. }\end{array}$ \\
\hline $\mathrm{NaCl}$ & 5.9 & 5.1 & 5.7 & -0.6 \\
$\mathrm{KCl}$ & 4.5 & 3.9 & 5.3 & -1.4 \\
$\mathrm{KBr}$ & 4.0 & 3.5 & 4.7 & -1.2 \\
\hline
\end{tabular}

For the solubilities of the inert gases in fluoride melts, it has been found in general that the ratio $K_{\text {obs }} / K_{\text {calc }}$ is less than unity, but also that it increases with increasing size of the solute molecule. ${ }^{7-9}$ This trend is also observed for the still larger $\mathrm{CO}_{2}$ molecule where the ratio is around unity, cf. Fig. 9. (For argon in molten sodium nitrate, on the other hand, Copeland and Zybko ${ }^{23}$ observed much higher solubilities, which might indicate that the simple model of Uhlig ${ }^{20}$ is not equally applicable to this type of salt.) The deviation between experimental and calculated slopes has been discussed by Blander et al. ${ }^{8}$

It should be pointed out that the calculated $K$ values are quite sensitive to the value of the area $A$. The surface area of the $\mathrm{CO}_{2}$ molecule represents a minimum value for the area of the necessary hole. Any thermal motion of the molecule would necessitate a larger hole. A maximum value is obtained by assuming completely free rotation of the $\mathrm{CO}_{2}$ molecule, the area will then be the surface of a sphere with diameter 5.12 $\AA$. This gives nearly twice the $\mathrm{A}$ value used above and results in values of $K$ almost a power of ten lower than those indicated by the dashed lines in Fig. 9. This might be taken as indication that the $\mathrm{CO}_{2}$ molecule does not, in fact, occupy a hole much larger than its own size. But the strong dependence on the somewhat arbitrarily assessed area $A$ nevertheless implies that no very definite conclusion should be drawn from the good agreement shown in Fig. 9. A more detailed discussion will have to be deferred until further experimental data are available.

Acta Chem. Scand. 20 (1966) No. 7 
Appendix 1. The effect of nickel oxide

The solubilities obtained by the present methods are about a power of ten lower than those obtained by the first method ${ }^{1}$ where nickel containers were used. Chemical analysis of melt from the nickel container after the experiments showed the presence of $\mathrm{Ni}^{2+}$ ions in a concentration of about $10^{-6}$ mole $/ \mathrm{ml}$. The container was visibly corroded, and it is reasonable that the following reaction had taken place

$$
\mathrm{Ni}(\mathrm{s})+\mathrm{CO}_{2}(\mathrm{~g})=\mathrm{NiO}(\text { dissolved in melt })+\mathrm{CO}(\mathrm{g})
$$

From thermodynamic data ${ }^{24}$ the equilibrium constant for this reaction at $1100^{\circ} \mathrm{K}$ (calculated for pure solid $\mathrm{NiO}$ ) is 0.007 . The introduction of nickel oxide in the melt will increase its basicity and consequently increase the solubility of $\mathrm{CO}_{2}$.

To confirm these assumptions, the solubility of $\mathrm{CO}_{2}$ was determined by the thermogravimetric method for molten sodium chloride with added nickel oxide corresponding to about $10^{-6}$ moles $\mathrm{Ni}^{2+} / \mathrm{ml}$. At $850^{\circ} \mathrm{C}$, the solubility of $\mathrm{CO}_{2}$ was found to be about 4 times larger than in pure sodium chloride.

\section{Appendix 2. Rate of dissolution of $\mathrm{CO}_{2}$ in molten sodjum chloride}

The theoretical curve in Fig. 5 is valid for diffusion in a solid, while the experimental points have been observed for a liquid. With this in mind, the agreement is surprisingly good. Assuming that convection is negligible, an upper limit for the diffusivity may be calculated from the data of Fig. 5. The straight part of the theoretical curve may be represented by the general expression $F=1.13 \sqrt{D t} / L$ or

$$
D=\frac{1.28}{L^{2}}\left(\frac{F}{\sqrt{t}}\right)^{2}
$$

where $D$ is diffusivity, $t$ is time and $L$ is a characteristic dimension of the sample, here the depth of the liquid salt. The mean of the calculated $D$ values from 9 runs in the temperature range $830-890^{\circ} \mathrm{C}$ is $D=6.5 \pm 1.0 \times 10^{-3} \mathrm{~cm}^{2}$ $\sec ^{-1}$.

From the theoretical relation $D=u k T$, where $u$ is the mobility from Stoke's law, one obtains for the $\mathrm{CO}_{2}$ molecule in molten $\mathrm{NaCl}, D=5 \times 10^{-5}$ $\mathrm{cm}^{2} \mathrm{sec}^{-1}$. This is also the order of magnitude generally found for diffusivities in liquids ${ }^{25}$ including self-diffusion in molten salts. ${ }^{26}$ The diffusivity derived from the present observations is thus two orders of magnitude higher than would be expected. It appears probable that liquid convection has been sufficiently rapid so that the rate of dissolution has not been governed by diffusion.

It may be noted in this connection that the anomalously high coefficient of self-diffusion reported for the anion in sodium carbonate ${ }^{27}$ has been refuted by the subsequent work of Spedding and Mills. ${ }^{28}$ The diffusivity of $\mathrm{Cl}_{2}$ gas in molten alkali halides was recently measured by Ryabukhin, ${ }^{29}$ with results of 
the order of $10^{-3} \mathrm{~cm}^{2} \mathrm{sec}^{-1}$. Again it may be doubted whether the chronopotentiometric method used has not been influenced by convection (cf. Sundheim ${ }^{26,}$ p. ${ }^{256}$ ). The dependence of diffusivity on temperature reported by Ryabukhin is, in any case, entirely unacceptable.

The influence of convection in the present case is further supported by an estimate of the rate of convection by means of the equations given by Bird, Stewart and Lightfoot, ${ }^{30}$ introducing the viscosity, density and coefficient of thermal expansion for liquid sodium chloride. Although the boundary conditions in the present case do not permit a strictly quantitative calculation, the results indicate that a temperature gradient of $0.1^{\circ} \mathrm{C}$ from the center of the cell (Fig. 3) to the cylinder wall will cause free convection to an extent which is ample to explain the observed rates of dissolution. Since temperature differences larger than $0.1^{\circ}$ are quite likely to occur in the crucible zone of the furnace, the calculations indicate that neither diffusion nor convection has been rate determining.

As a third alternative, the rate determining step is assumed to be the transfer of $\mathrm{CO}_{2}$ molecules from the gas to the liquid phase. This process may be treated theoretically in different ways which lead to the same type of equation

$$
\ln (1-F)=-k t
$$

where $F$ is fractional saturation, $t$ is time and $k$ is a constant. When the results from the thermogravimetric method are plotted as $\ln (1-F)$ against time, straight lines are actually obtained, up to about $F=0.95$. This type of plot may also be used for extrapolation to zero time to obtain the total amount dissolved, as explained previously in connection with Fig. 5. The starting points obtained by the two methods of plotting do not quite coincide, the solubilities obtained from the graphs of $\ln (1-F)$ versus $t$ are 10 to $15 \%$ lower than those obtained from graphs of the type shown in Fig. 5. The assumption of a reaction hindrance at the surface of the molten salt appears to be a more reasonable approach than that of diffusion, consequently the solubilities from the gravimetric method should possibly be 10 to $15 \%$ lower than those plotted in Fig. 8. The difference (about 0.05 log units in Fig. 5) is still within the experimental spread.

Acknowledgement. The authors wish to thank the Royal Norwegian Council for Scientific and Industrial Research, and Norges tekniske høgskoles fond, for financial support in this work. Thanks are extended to Mr. T. Selsbakk for his careful work in carrying out a number of the measurements.

\section{REFERENCES}

1. Grjotheim, K., Heggelund, P., Krohn, C. and Motzfeldt, K. Acta Chem. Scand. 16 (1962) 689.

2. Haupin, W. E. J. Electrochem. Soc. 107 (1960) 232.

3. Førland, T., Storegraven, H. and Urnes, S. Z. anorg. allgem. Chem. 279 (1955) 205.

4. Kröger, C. and Goldmann, N. Glastechn. Ber. 35 (1962) 459.

5. Pearce, M. L. Internal Report, Pennsylvania State University 1964.

6. Ryabukhin, Yu. M. Russ. J. Inorg. Chem. 7 (1962) 565.

7. Grimes, W. R., Smith, N. V. and Watson, G. M. J. Phys. Chem. 62 (1958) 862.

Acta Chem. Scand. 20 (1966) No. 7 
8. Blander, M., Grimes, W. R., Smith, N. V. and Watson, G. M. J. Phys. Chem. 63 (1959) 1164.

9. Watson, G. M., Evans, R. B., Grimes, W. R. and Smith, N. V. J.Chem. Eng. Data 7 (1962) 285.

10. Krohn, C. Tidsskr. Kjemi Bergvesen Met. 21 (1961) 822.

11. Motzfeldt, K. In Physicochemical Measurements at High Temperatures, Eds. Bockris, J. O'M., White, J. L. and Mackenzie, J. D., Butterworths, London 1960, p. 51-53.

12. Diels, K. and Jaeckel, R. Leybold Vakuum-Taschenbuch, 2nd. Ed., Springer, Berlin 1962, p. 205; Data from van Amerongen, G. J. J. Appl. Phys. 17 (1946) 972.

13. Motzfeldt, K. Unpublished work.

14. Bratland, D. Måling av opplöseligheten av $\mathrm{CO}_{2} i$ saltsmelter, Thesis, The Technical University of Norway, December 1962.

15. Vogel, E., Schinke, H. and Sauerwald, F. Z. anorg. allgem. Chem. 284 (1956) 131.

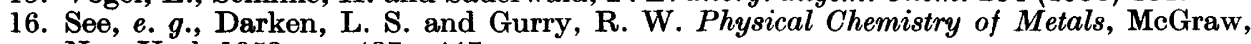
New York 1953, pp. 437-447.

17. Van Artsdalen, E. R. and Yaffe, I. S. J. Phys. Chem. 59 (1955) 118.

18. Motzfeldt, K. J. Phys. Chem. 59 (1955) 139.

19. Selman, G. L., Spender, M. R. and Darling, A. S. Platinum Metals Rev. 9 (1965) 130.

20. Uhlig, H. H. J. Phys. Chem. 41 (1937) 1215.

21. Pauling, L. Nature of the Chemical Bond, 3rd. Ed., Cornell University Press, Ithaca, N. Y. 1960 , pp. 260 and 267.

22. Bloom, H., Davis, F. G. and James, D. W. Trans. Faraday Soc. 56 (1960) 1179; Bloom, H. and Bockris, J. O'M. In Modern Aspects of Electrochemistry 2, Ed. Bockris, J. O'M., Butterworths, London 1959, p. $160 \mathrm{ff}$.

23. Copeland, J. L. and Zybko, W. C. J. Phys. Chem. 69 (1965) 3631.

24. Wicks, C. E. and Block, F. E. Bureau of Mines Bull. 605, Washington 1963.

25. Jost, W. Diffusion, Academic, New York 1960, pp. 474-479.

26. Sundheim, B. R. In Fused Salts, Ed. Sundheim, B. R., McGraw, New York 1964, pp. 224-231.

27. Djordjevic, S. and Hills, G. J. Trans. Faraday Soc. 56 (1960) 269.

28. Spedding, P. L. and Mills, R. J. Electrochem. Soc. 112 (1965) 594.

29. Ryabukhin, Yu. M. Zh. Fiz. Khim. 39 (1965) 2927.

30. Bird, R. B., Stewart, W. E. and Lightfoot, E. N. Transport Phenomena, Wiley, New York 1960, pp. 297-300.

Received March 19, 1966. 